\title{
GMR
}

\section{Effects of alendronate on osteoporosis treatment and levels of related cytokines}

\author{
C.T. Liu ${ }^{1}$, X.J. Yuan ${ }^{2}$ and G.C. Gao ${ }^{3}$ \\ ${ }^{1}$ Department of Orthopedics, Medical College of Nanchang University, Nanchang, \\ Jiangxi, China \\ ${ }^{2}$ Department of Neurology, Gaoan People's Hospital, Gaoan, Jiangxi, China \\ ${ }^{3}$ Department of Orthopedics, \\ The Second Affiliated Hospital of Nanchang University, Nanchang, Jiangxi, \\ China \\ Corresponding author: C.T. Liu \\ E-mail: changtieliu@163.com \\ Genet. Mol. Res. 16 (1): gmr16019485 \\ Received October 27, 2016 \\ Accepted January 19, 2017 \\ Published March 16, 2017 \\ DOI http://dx.doi.org/10.4238/gmr16019485 \\ Copyright $(2017$ The Authors. This is an open-access article distributed under the terms of \\ the Creative Commons Attribution ShareAlike (CC BY-SA) 4.0 License.
}

\begin{abstract}
Alendronate regulates the activity of osteoclasts and healing of osteoporosis. This study investigated the effect of alendronate on bone healing and changes in the levels of cytokines. Bilateral ovaries of 10 adult female rabbits were removed surgically in aseptic condition to establish the animal model of osteoporosis. Five rabbits in group A were treated with alendronate $\left(1.15 \mathrm{mg} \cdot \mathrm{kg}^{-1} \cdot \mathrm{week}^{-1}\right)$ once a week by a stomach tube, whereas the remaining 5 in group B were treated with physiological saline. The success of the animal model establishment and the efficacy of alendronate treatment were evaluated by the sports ability score and the Basso, Beattie, and Bresnahan (BBB) score; the healing degree of osteoporosis was determined by X-ray analysis and measurement of biomechanical properties; the changes in the levels of related cytokines were measured by enzyme-linked immunosorbent assay (ELISA) and immunohistochemical staining. Treatment improved dyskinesia of the animals in group A than that in group B,
\end{abstract}

Genetics and Molecular Research 16 (1): gmr16019485 
with significant improvement occurring in the 4th week of treatment. The BBB score of the group A animals revealed movements similar to normal, but that of the group B animals exhibited significant motor disturbance $(\mathrm{P}<0.01)$. X-ray examination showed that with time, the $\mathrm{X}$-ray ratings increased. Measurement of the biomechanical properties further showed that alendronate had a positive effect on osteoporosis healing. The results of ELISA and immunohistochemistry showed that the levels of ALP, BMP-2, bFGF, and IGF-1 were upregulated in group A. In conclusion, alendronate accelerated osteoporosis healing probably via certain cytokine-related mechanism.

Key words: Osteoporosis; Alendronate; ALP; BMP-2; bFGF; IGF-1

\section{INTRODUCTION}

Osteoporosis is a disease characterized by bone calcification and pain, which significantly influences and inconveniences the daily lives of the patients. Despite the advances in modern medical technology, the number of patients whose gait is compromised by osteoporosis is significantly high (Yun et al., 2010; Bess, 2013). Osteoporosis is grouped into primary and secondary injuries. The secondary injury is irreversible; compared to the primary injury, the secondary injury can cause a series of pathological changes, such as tissue ischemia, edema, and inflammatory reaction (Ettinger et al., 2010; Leslie et al., 2010; Pencina et al., 2011). Alendronate affects bone metabolism by regulating the activity of osteoclasts. It is released upon osteoclast-mediated dissolution of calcium crystals in the bone, which simultaneously inhibits regeneration of osteoclasts and increases the amount of osteoblasts, thereby indirectly inhibiting bone resorption (Pressman et al., 2011).

Several factors are demonstrated to play important roles in the regulation of bone cell differentiation, repair of damage tissues, as well as the proliferation of cartilage cells, such as alkaline phosphatase (ALP), the 114-amino acid-long bone morphogenetic protein-2 (BMP-2), basic fibroblast growth factor (bFGF) and insulin-like growth factor 1 (IGF-1). ALP is a bipolymeric protein with a molecular weight of $56 \mathrm{kDa}$, which is composed of 449 amino acids, with each polymer having an active center. The main function of ALP is to synthesize the monomeric precursors of ALP with amino terminal signal peptides in the cytoplasm. Levels of ALP increase during two conditions: a physiological increase occurs during childhood skeletal development when ALP levels are twice as high as that in adults, and a pathological increase, which occurs in liver diseases such as liver cirrhosis and cancer (Donaldson et al., 2011). BMP-2is a member of the transforming growth factor $\beta$ superfamily, which induces transformation of mesenchymal cells into cartilage cells, there by promoting bone cell differentiation and accelerating the repair of bone injury (Xu et al., 2005). bFGF is a cytokine secreted by the pituitary gland, which promotes fibroblast growth in the brain, neural tissue, and blood; its main functions are to promote cell regeneration, repair of damaged tissue, and to act as a nerve nourishment factor (Eiselleova et al., 2009). (IGF-1) is similar to insulin in its molecular structure. It promotes physiological growth by influencing glycogen synthesis and lactic acid secretion, which can lower levels of blood sugar, triglycerides, and polar density lipoproteins in the blood. Studies have shown that IGF-1 also promotes the proliferation of cartilage cells and synthesis of the cartilage matrix (Nohe et al., 2002; Adler et

Genetics and Molecular Research 16 (1): gmr16019485 
al., 2010; Mohanraj and Oh, 2011). Given their roles in the regulation of bone cells, whether these four factors mentioned above are involved in the bone healing process remains poorly understood.

Given the critical role in the regulation of bone metabolism, whether Alendronate affects bone healing remains unclear. The aim of the present study was to investigate the effect of Alendronate in bone healing.

\section{MATERIAL AND METHODS}

\section{Reagents and equipment}

Rabbits were purchased from the Medical College of Nanchang University. Alendronate was purchased from Sigma (St. Louis, MO, USA). Reagents for enzyme-linked immunosorbent assay (ELISA) (ALP ELISA kit, BMP-2 ELISA kit, bFGF ELISA kit and IGF-1 ELISA kit) were procured from Wuhan Boster Biological Technology Ltd (Wuhan, Hubei, China). Primary antibodies for ALP, BMP-2, bFGF, and IGF-1 and rat-anti-rabbit antibody were purchased from Santa Cruz (Dallas, Texas, USA); anti-rat secondary antibody and EDTA repair liquid were purchased from Zhongshan Golden Bridge Biotechnology Company Pvt. Ltd. (Beijing, China). A Zeiss fluorescence microscope was used for imaging immunohistochemistry specimens (LSM800, Zeisis, Oberkochen, Germany).

\section{Development of the osteoporosis model}

Ten adult female rabbits were randomly divided into two groups, with 5 animals each in the control and experimental groups. The bilateral ovaries of all the rabbits were surgically removed under aseptic condition to establish the animal models of osteoporosis according to previously published studies (Yang et al., 1997; Wang et al., 2015). The rabbits in the experimental group (group A) were treated once a week with alendronate $(1.15 \mathrm{mg} \cdot \mathrm{kg}$ ${ }^{1}$. week $^{-1}$ ) by using a stomach tube and those in the control group (group B) were treated with the equivalent amount of physiological saline solution. The proximal femur and 3D reconstructions were scanned and analyzed with animal micro-computed tomography (CT) 4 weeks after the surgery; bone densities were analyzed with dual-energy X-ray detection; bone mechanical strengths were compared by biomechanical experiments. The spinal cords of the successfully modeled rabbits were built into middle open osteoporosis model with the Kirschner wire for internal fixation.

All the procedures that were performed on the animals were approved by the Animal Ethics Committee of the Medical College of Nanchang University.

\section{Evaluation of the animal model}

Movement disorder classification was assessed according to a previous study (Fahn et al., 2011). The bladders of the animals were emptied before acceptance of the test, followed by adaptation in the test environment for 5-10 minutes, after which the test was started. The test was scored in a scale of 0-9 points. Stable body with normal movement was scored as 9 points; 5-8 points indicated the posterior extreme positions of the hind legs and the mutual coordination between the front and hind legs during travel; 3-4 scores indicated the conditions

Genetics and Molecular Research 16 (1): gmr16019485 
of the hind legs while supporting the bust and while moving forward; 0 to 2 scores indicated ankle movement.

Basso, Beattie, and Bresnahan (BBB) scores were evaluated according to a previous study (Manjhi et al., 2013). Rabbits in the two groups were forced to walk for 15-30 minutes at 22:00 h every night and their walking trajectories were mapped, according to which the walking status was scored. A normal walk scored more than 25 points, an irregular walk 15 to 25 points, walking with difficulty scored 5-15 points, and a difficult walk scored less than 5 points.

\section{Immunohistochemistry}

Tissues were fixed overnight in formalin followed by $3 \mathrm{~h}$ of dehydration in $70 \%$ ethanol and $80 \%$ ethanol, respectively. This was followed by $2 \mathrm{~h}$ incubation in $95 \%$ ethanol, 2 changes of $100 \%$ ethanol ( $1.5 \mathrm{~h}$ each), 2 changes of xylene ( $0.5 \mathrm{~h}$ each), 2 changes of paraffin (one for $1 \mathrm{~h}$ and another for $2 \mathrm{~h}$ both at $60^{\circ} \mathrm{C}$ ). The tissues were then sliced into $3-\mu \mathrm{m}$-thick pieces by conventional methods (Levingstone et al., 2016). The specimens were dewaxed according to the conventional dewaxing method (Levingstone et al., 2016). Briefly, the slices were incubated successively for 10 minutes in each of the following solutions-xylene, anhydrous ethanol, $95 \%$ ethanol, $90 \%$ ethanol, $85 \%$ ethanol, and $80 \%$ ethanol, followed by washing thrice with PBS for $5 \mathrm{~min}$. Thereafter, the specimens were repaired with sodium citrate solution, $\mathrm{pH}$ 6.0 , for 5 minutes and washed thrice with PBS for $5 \mathrm{~min}$. Then they were incubated with $10 \%$ BSA for $30 \mathrm{~min}$ (blocking step), followed by overnight incubation with primary antibodies (1: 100 dilutions of rat-anti-rabbit monoclonal antibodies for ALP, BMP-1, bFGF, and IGF-1). The next day, the specimens were washed thrice with PBS for $5 \mathrm{~min}$, followed by incubation with anti-rat secondary antibody $\left(1: 100\right.$ dilution) at $37^{\circ} \mathrm{C}$ for $1 \mathrm{~h}$. Thereafter, the specimens were washed thrice with PBS for 5 min. Finally, DAB (3,3'-diaminobenzidine) development was conducted. S.

\section{ELISA}

Reagents and standards were prepared according to the manufacturer's instructions. Hundred microliter samples and standards were added in each well of a 96-well plate and incubated at $37^{\circ} \mathrm{C}$ for 90 min without washing. Then, $100 \mu \mathrm{L}$ biotin-marked antibody was added to each well and incubated at $37^{\circ} \mathrm{C}$ for $60 \mathrm{~min}$, followed by washing thrice with 0.01 $\mathrm{M}$ tris-buffered saline (TBS). Thereafter, $100 \mu \mathrm{L}$ ABC reagent was added to each well and incubated at $37^{\circ} \mathrm{C}$ for $30 \mathrm{~min}$. Finally, the wells were washed with $0.01 \mathrm{M}$ TBS 5 times, TMB was added and the plate was incubated at $37^{\circ} \mathrm{C}$ in the dark for $30 \mathrm{~min}$.

\section{X-ray analysis and biomechanical examination}

Three rabbits were selected randomly from each group at 1, 2, and 4 weeks after establishment of the osteoporosis model for X-ray examination and the results were evaluated per the criteria reported in literature (Boyne et al., 2005). After sample collection from the animals' tissues and organs, the universal mechanical determination method was conducted. $\mathrm{L}$ denotes span length of $35 \mathrm{~mm}, \mathrm{P}$ denotes pressure, and bending strength formula was calculated by the formula $8 \mathrm{PL} / \mathrm{pd} 3$.

Genetics and Molecular Research 16 (1): gmr16019485 


\section{Statistical analysis}

Three independent experiments were performed for each assay. All data were processed by the SPSS 11.0 software and are reported as means \pm standard deviation (SD). The student's $t$-test was used for comparing the differences between the two groups. Two-way ANOVA was performed for comparing the significance between the two groups. Immunohistochemistry images were analyzed by the Image-J software (Rawak Software, Inc., Germany). P $<0.05$ indicated that the difference was statistically significant.

\section{RESULTS}

\section{Analysis of the effect of alendronate on the treatment of osteoporosis}

Upon successfully establishing the rabbit spinal osteoporosis model, we treated the rabbits in groups A and B with alendronate and physiological saline solution, respectively. Thereafter, we observed the bodily movements of the animals from both the groups by the motion obstacle detection method (Chun et al., 2012) and graded them according to the dyskinesia classification system into two groups (group A and B). The results showed that the movement disorders in the alendronate-treated group A animals improved significantly, especially after the 4 th week of treatment $(\mathrm{P}<0.01)$ (Figure $1 \mathrm{~A})$. BBB scores showed that the motions of the group A animals were almost normal, whereas motion disorders were apparent in the animals of group $\mathrm{B}(\mathrm{P}<0.01)$ (Figure $1 \mathrm{~B})$.
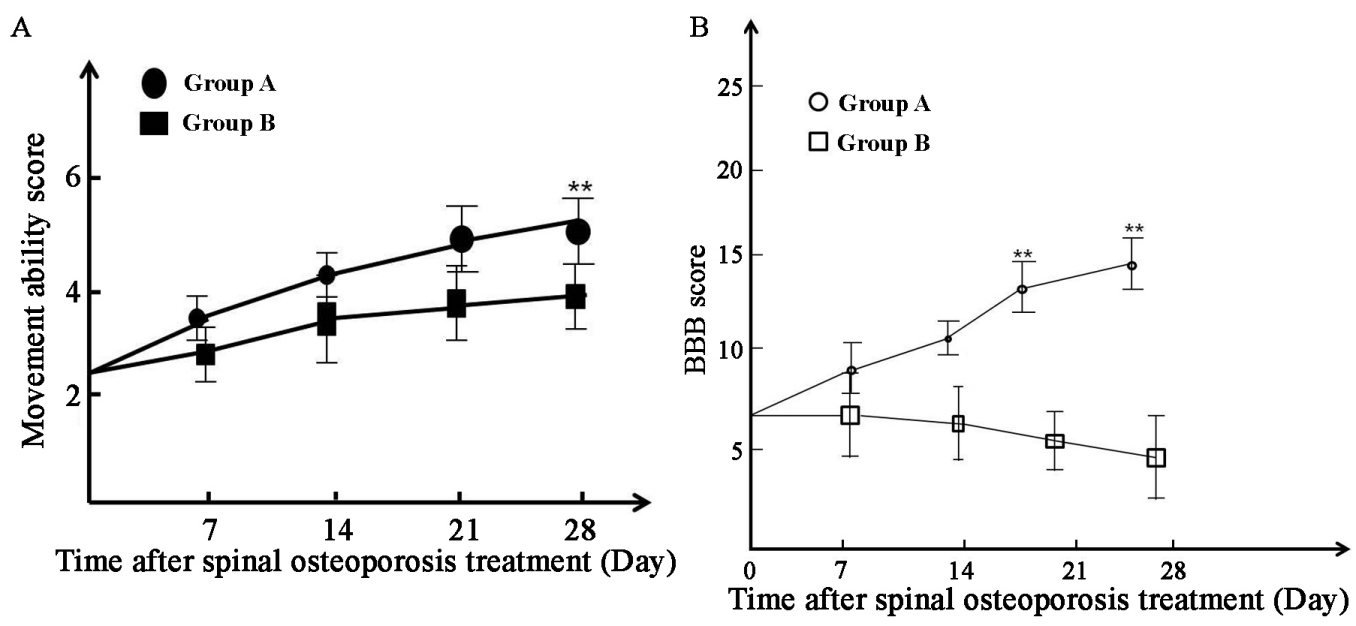

Figure 1. Comparison of the spinal osteoporosis models of the two groups. A. Graph showing the movement ability scores of the two groups (Group A: Alendronate group, Group B: Physiological saline group). B. Graph showing $\mathrm{BBB}$ scores of the two groups. Data are reported as means $\pm \mathrm{SD} . * * \mathrm{P}<0.01$.

\section{X-ray analysis and biomechanical examinations}

The proximal femurs were scanned and 3D reconstructed with animal micro-CT in the 8th week of treatment; bone mineral density of the two groups was assessed and analyzed

Genetics and Molecular Research 16 (1): gmr16019485 
with the dual energy X-ray detection method. The results showed that the X-ray scores increased with time, especially at the 4th week post-treatment (Figure 2). Determination of biomechanical properties indicated that alendronate had a positive effect on osteoporosis treatment (Figure 3).

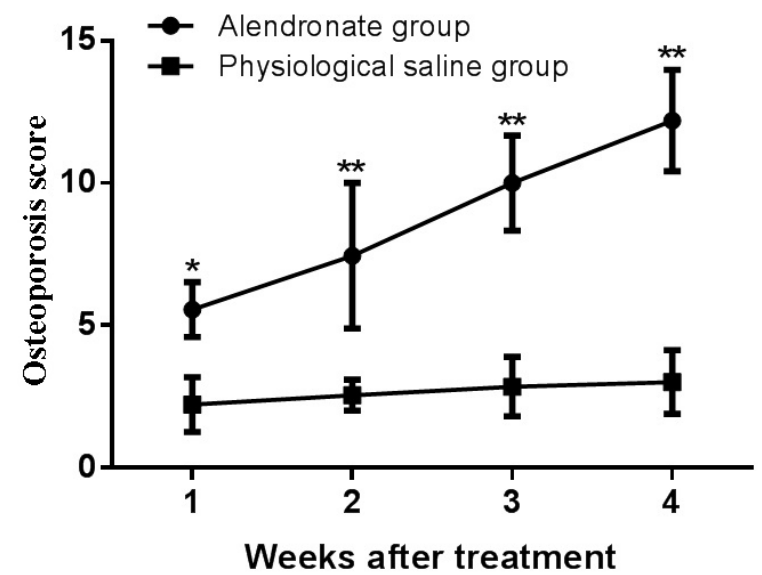

Figure 2. X-ray examination score of osteoporosis in the two model groups. Graph depicting the osteoporosis score in the two groups $(\mathrm{A}$ and $\mathrm{B})$. *indicates $\mathrm{P}<0.05, * *$ indicated $\mathrm{P}<0.01$. Data are reported as means $\pm \mathrm{SD}$.

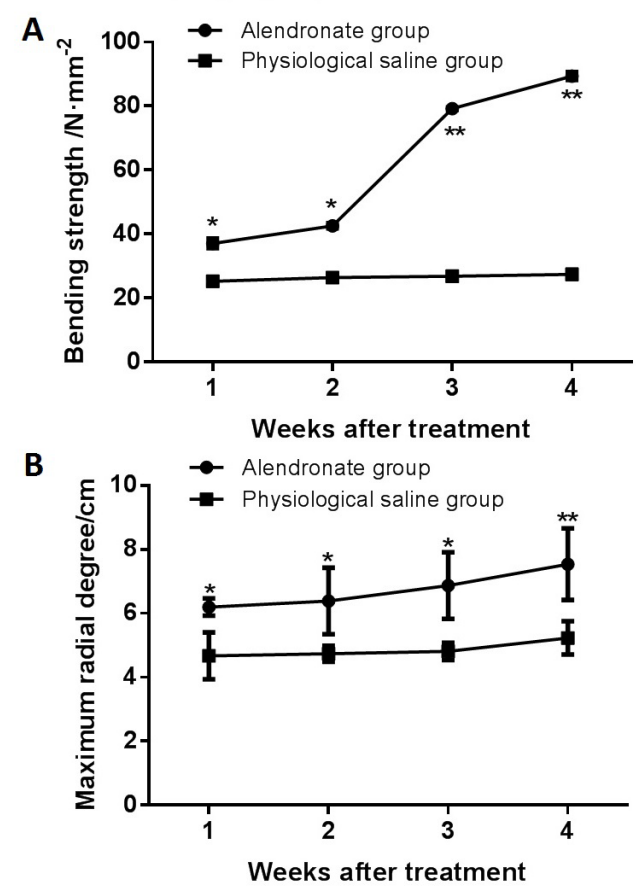

Figure 3. Determination of the biomechanical properties in the rabbit osteoporosis model. A. Graph showing bending strength. B. Graph showing maximum radial degree. $* \mathrm{P}<0.05 ; * * \mathrm{P}<0.01 ; * * * \mathrm{P}<0.001$. Data are reported as means $\pm \mathrm{SD}$.

Genetics and Molecular Research 16 (1): gmr16019485 


\section{Changes in the levels of ALP, BMP-2, bFGF, and IGF-1}

ELISA showed that the levels of ALP, BMP-2, bFGF, and IGF-1 increased to varying extents in the serum of the group A animals (Figure 4A). Immunohistochemistry further showed that the amounts of these cytokines were significantly elevated $(\mathrm{P}<0.05)$ in the tissues of the alendronate-treated animals than in the tissues of the saline-treated ones (Figure $4 \mathrm{~B}$ and $\mathrm{C}$ ).
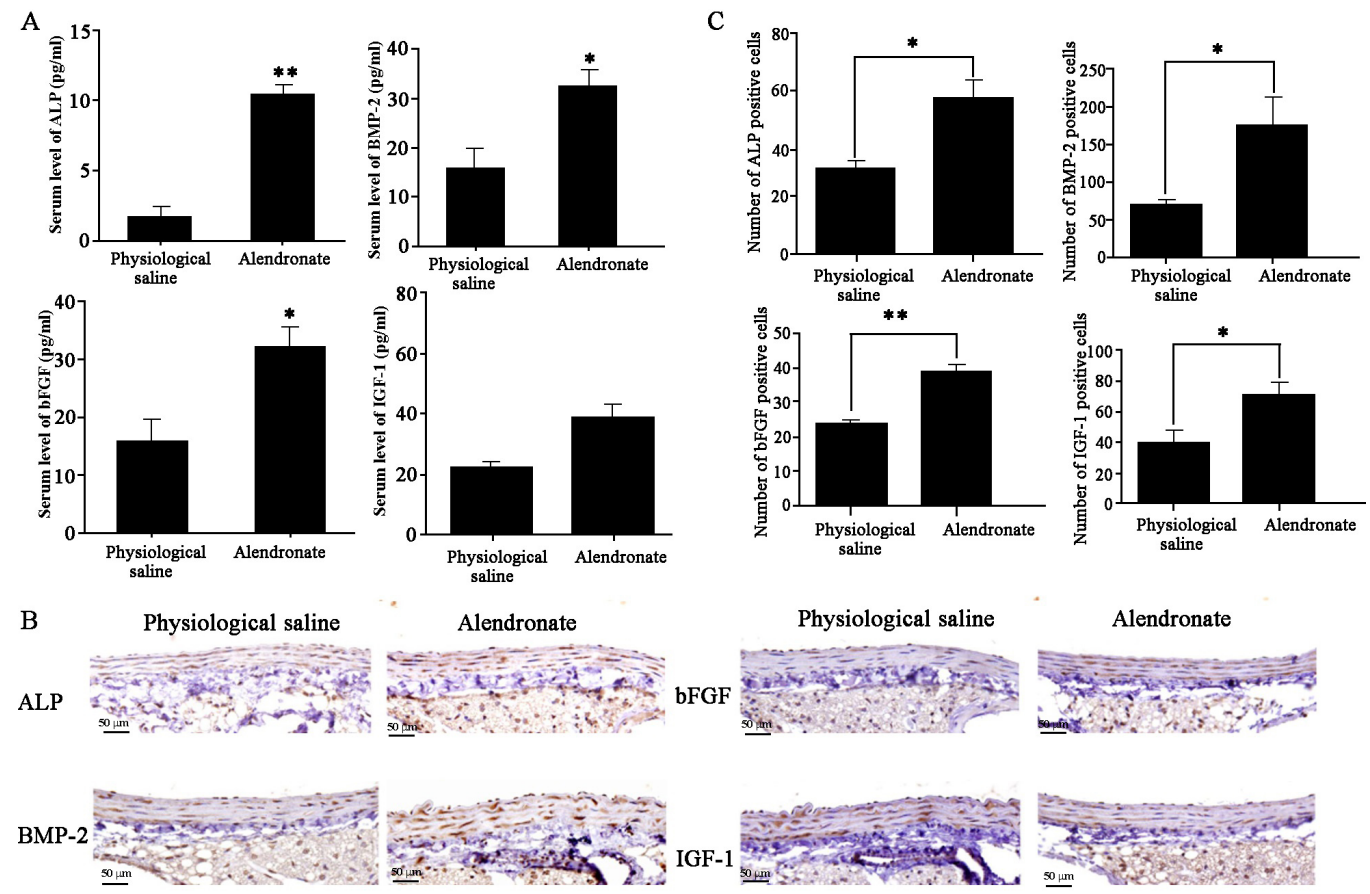

Figure 4. Changes in the levels of ALP, BMP-2, bFGF, and IGF-1 in the rabbit osteoporosis model. A. Bar graph showing the alterations in the levels of ALP, BMP-2, bFGF, and IGF-1 in group A and B animals as detected by ELISA. B. Immunohistochemical staining showing the alterations in levels of ALP, BMP-2, bFGF, and IGF-1 in the tissue specimens of group A and B animals (200X). (C) Bar graph showing the increase in the number of cells positive for ALP, BMP-2, bFGF, and IGF-1 after treatment with alendronate. ${ }^{*} \mathrm{P}<0.05$, $* * \mathrm{P}<0.01, * * * \mathrm{P}<0.001$.

\section{DISCUSSION}

Osteoporosis, which inconveniences the lives of patients, is mainly caused by calcification of bones as a result of traffic accidents, injuries, and physical damage, which eventually leads to a series of pathological damage and nerve function disorder. The physical damage elicits high nutritional demand for the repair of damaged tissue and cell proliferation (Trémollieres et al., 2010). The inflammation reaction caused by osteoporosis is more serious than that caused by brain damage. Despite extensive investigations on the pathogenesis of osteoporosis, such as studies on the changes in the composition of inflammatory cells in secondary injury, there is ambiguity in the results, the main reason for which is the difficulty in the separation of the inflammatory cells (Donaldson et al., 2009; Ensrud et al., 2009). 
Several factors influence osteoporosis, such as endocrine factors, genetic factors, and nutritional factors (in youth, the nutrients are used for synthesis of bone matrix, which is critical for bone growth) (Ensrud et al., 2009; Johansson et al., 2010; Pluskiewicz et al., 2010). Alendronate promotes bone regeneration and healing of bone tissue damage by decreasing the number of osteoclasts and increasing the number of osteoblasts, which is observed in osteoporosis (Pressman et al., 2011). It was recently reported that ALP inhibits inflammatory reactions by activating caspase 3 (Sandhu et al., 2010) and that bFGF promotes neuroendocrine release in prostate cancer (Kanis et al., 2011). Studies have reported that after treatment of osteoporosis by alendronate, levels of cytokines such as ALP, BMP-2, bFGF, and IGF-1 were altered in vivo. In this study, we show that the levels of ALP, BMP-2, bFGF, and IGF-1 in the serum of alendronate-treated animals were higher than those in the serum of saline-treated animals. Additionally, immunohistochemistry also showed that the numbers of ALP, BMP-2, bFGF, and IGF-1 positive cells in the tissues of the alendronate-treated group were more than those in the physiological saline-treated group, indicating that these cytokines were highly expressed after alendronate treatment in our spinal osteoporosis models. Earlier studies have reported that these cytokines can promote the formation of new fibroblasts and inhibit generation of osteoclasts in patients with osteoporosis (Osta et al., 2014). Therefore, we speculate that alendronate promotes bone healing possibly through upregulation of ALP, BMP-2, bFGF, and IGF-1. However, the exact mechanism by which alendronate regulates the levels of these cytokines is unclear and requires further investigation. In addition, these four cytokines may also cross-regulate each other's expression, which requires further investigation.

\section{CONCLUSION}

In conclusion, alendronate can accelerate osteoporosis healing possibly through regulation of the secretion of cytokines such as ALP, BMP-2, bFGF, and IGF-1.

\section{Conflicts of interest}

The authors declare no conflict of interest.

\section{ACKNOWLEDGMENTS}

We thank the anonymous reviewers for reviewing this manuscript.

\section{REFERENCES}

Adler RAHF, Hastings FW and Petkov VI (2010). Treatment thresholds for osteoporosis in men on androgen deprivation therapy: T-score versus FRAX. Osteoporos. Int. 21: 647-653. http://dx.doi.org/10.1007/s00198-009-0984-0

Bess DH (2013). A revised clinician's guide to the prevention and treatment of osteoporosis. J. Clin. Endocrinol. Metab. 93: 2463-2465.

Boyne PJ, Lilly LC, Marx RE, Moy PK, et al. (2005). De novo bone induction by recombinant human bone morphogenetic protein-2 (rhBMP-2) in maxillary sinus floor augmentation. J. Oral Maxillofac. Surg. 63: 1693-1707. http://dx.doi. org/10.1016/j.joms.2005.08.018

Chun SY, Reese TG, Ouyang J, Guerin B, et al. (2012). MRI-based nonrigid motion correction in simultaneous PET/MRI. J. Nucl. Med. 53: 1284-1291. http://dx.doi.org/10.2967/jnumed.111.092353

Donaldson MG, Cawthon PM, Schousboe JT, Ensrud KE, et al.; Study of Osteoporotic Fractures (SOF) (2011). Novel

Genetics and Molecular Research 16 (1): gmr16019485 
methods to evaluate fracture risk models. J. Bone Miner. Res. 26: 1767-1773. http://dx.doi.org/10.1002/jbmr.371

Donaldson MG, Palermo L, Schousboe JT, Ensrud KE, et al. (2009). FRAX and risk of vertebral fractures: the fracture intervention trial. J. Bone Miner. Res. 24: 1793-1799. http://dx.doi.org/10.1359/jbmr.090511

Eiselleova L, Matulka K, Kriz V, Kunova M, et al. (2009). A complex role for FGF-2 in self-renewal, survival, and adhesion of human embryonic stem cells. Stem Cells 27: 1847-1857. http://dx.doi.org/10.1002/stem.128

Ensrud KE, Lui LY, Taylor BC, Schousboe JT, et al.; Study of Osteoporotic Fractures Research Group (2009). A comparison of prediction models for fractures in older women: is more better? Arch. Intern. Med. 169: 2087-2094. http://dx.doi.org/10.1001/archinternmed.2009.404

Ettinger B, Black DM, Dawson-Hughes B, Pressman AR, et al. (2010). Updated fracture incidence rates for the US version of FRAX. Osteoporos. Int. 21: 25-33. http://dx.doi.org/10.1007/s00198-009-1032-9

Fahn S (2011). Classification of movement disorders. Mov. Disord. 26: 947-957.

Johansson H, Kanis JA, Mccloskey EV, Odén A, et al. (2010). A FRAX(R) model for the assessment of fracture probability in Belgium. Osteoporos. Int. 22: 22.

Kanis JA, Johansson H, Oden A and McCloskey EV (2011). Guidance for the adjustment of FRAX according to the dose of glucocorticoids. Osteoporos. Int. 22: 809-816. http://dx.doi.org/10.1007/s00198-010-1524-7

Leslie WD, Lix LM, Johansson H, Oden A, et al.; Manitoba Bone Density Program (2010). Independent clinical validation of a Canadian FRAX tool: fracture prediction and model calibration. J. Bone Miner. Res. 25: 2350-2358. http:// dx.doi.org/10.1002/jbmr.123

Levingstone TJ, Thompson E, Matsiko A, Schepens A, et al. (2016). Multi-layered collagen-based scaffolds for osteochondral defect repair in rabbits. Acta Biomater. 32: 149-160. http://dx.doi.org/10.1016/j.actbio.2015.12.034

Manjhi J, Kumar S, Behari J and Mathur R (2013) Effect of extremely low frequency magnetic field in prevention of spinal cord injury-induced osteoporosis. J. Rehabil. Res. Dev. 50: 17-30.

Mohanraj L and Oh Y (2011). Targeting IGF-I, IGFBPs and IGF-I receptor system in cancer: the current and future in breast cancer therapy. Recent Patents Anticancer. Drug Discov. 6: 166-177. http://dx.doi.org/10.2174/157489211795328512

Nohe A, Hassel S, Ehrlich M, Neubauer F, et al. (2002). The mode of bone morphogenetic protein (BMP) receptor oligomerization determines different BMP-2 signaling pathways. J. Biol. Chem. 277: 5330-5338. http://dx.doi. org/10.1074/jbc.M102750200

Osta B, Benedetti G and Miossec P (2014). Classical and Paradoxical Effects of TNF- $\alpha$ on Bone Homeostasis. Front. Immunol. 5: 48. http://dx.doi.org/10.3389/fimmu.2014.00048

Pencina MJ, D'Agostino RB, Sr. and Steyerberg EW (2011). Extensions of net reclassification improvement calculations to measure usefulness of new biomarkers. Stat. Med. 30: 11-21. http://dx.doi.org/10.1002/sim.4085

Pluskiewicz W, Adamczyk P, Franek E, Leszczynski P, et al. (2010). Ten-year probability of osteoporotic fracture in 2012 Polish women assessed by FRAX and nomogram by Nguyen et al.-Conformity between methods and their clinical utility. Bone 46: 1661-1667. http://dx.doi.org/10.1016/j.bone.2010.02.012

Pressman AR, Lo JC, Chandra M and Ettinger B (2011). Methods for assessing fracture risk prediction models: experience with FRAX in a large integrated health care delivery system. J. Clin. Densitom. 14: 407-415. http://dx.doi. org/10.1016/j.jocd.2011.06.006

Sandhu SK, Nguyen ND, Center JR, Pocock NA, et al. (2010). Prognosis of fracture: evaluation of predictive accuracy of the FRAX algorithm and Garvan nomogram. Osteoporos. Int. 21: 863-871. http://dx.doi.org/10.1007/s00198-009$\underline{1026-7}$

Trémollieres FA, Pouillès JM, Drewniak N, Laparra J, et al. (2010). Fracture risk prediction using BMD and clinical risk factors in early postmenopausal women: sensitivity of the WHO FRAX tool. J. Bone Miner. Res. 25: 1002-1009. http://dx.doi.org/10.1002/jbmr.12

Wang ZX, Chen C, Zhou Q, Wang XS, et al. (2015). The treatment efficacy of bone tissue engineering strategy for repairing segmental bone defects under osteoporotic conditions. Tissue Eng. Part A 21: 2346-2355.

Xu RH, Peck RM, Li DS, Feng X, et al. (2005). Basic FGF and suppression of BMP signaling sustain undifferentiated proliferation of human ES cells. Nat. Methods 2: 185-190. http://dx.doi.org/10.1038/nmeth744

Yang X, Cai G, Wei L, Hou J, et al. (1997). Primary study on the use of ovariectomized rabbits for establishment of osteoporosis model. Sheng Wu Yi Xue Gong Cheng Xue Za Zhi 14: 353-358.

Yun H, Delzell E, Ensrud KE, Kilgore ML, et al. (2010). Predicting hip and major osteoporotic fractures using administrative data. Arch. Intern. Med. 170: 1940-1942. http://dx.doi.org/10.1001/archinternmed.2010.410

Genetics and Molecular Research 16 (1): gmr16019485 